\title{
ПУБЛИЧНОЕ ВЫСТУПЛЕНИЕ КАК ЧАСТЬ СОЗДАНИЯ ИМИДЖА ПОЛИТИКА (НА ПРИМЕРЕ ГРИГОРИЯ ЗИНОВЬЕВА)
}

\section{PUBLIC SPEAKING AS PART OF CREATING A POLITICIAN'S IMAGE (ON THE EXAMPLE OF GRIGORY ZINOVIEV)}

\section{Kuchmenko}

Summary: The article is devoted to public speaking as an integral part of activities of the politician. Various strategies are being considered to enhance the impact of public speaking on the audience. The speech behavior of Grigory Zinoviev was investigated and his role in the politician 's image formation was determined in general. Communication culture and speech literacy play an essential role in shaping the image of a politician, while the ability to convincingly and argumentatively express its political views is an integral part of the successful activity of a politician. The authors conclude the sighificant role of the speech image in the politician's image formation.

Keywords: politician's image, the speech image, protocol, public speaking, public activities.

\author{
Кучменко Марина Александровна \\ К.филол.н., старший преподаватель, Кубанский \\ государственный университет, Краснодар \\ kuchmenko_m0406@mail.ru
}

Аннотация: В статье рассматриваются публичные выступления как неотъемлемая часть деятельности политика. Автором статьи исследуются и сопоставляются различные речевые стратегии, позволяющие усилить эффективность воздействия публичного выступления на аудиторию. Исследовано речевое поведение Григория Зиновьева и определена его роль в формировании образа политика в целом.

Коммуникативная культура и грамотность речи играют существенную роль в формировании образа общественного деятеля, при этом способность убедительно и аргументированно излагать свои политические взгляды является неотъемлемой частью успешной деятельности политика. Автор приходит к выводу о значимой роли речевого имиджа в формировании образа политика в целом.

Ключевые слова: имидж политика, речевой имидж, протокол, публичное выступление, публичная деятельность.
$\mathrm{M}$ ногим известны имена политиков, чьи публичные выступления остались в памяти целых народов, а иногда даже способствовали изменению хода истории. Такие политики, как Ленин, Сталин, Хрущев, Рузвельт, Черчилль стали популярны не только из-за своих политических взглядов и принятых решений; их имена вошли в историю еще и благодаря тем незаурядным ораторским способностям, которые позволили превратить каждый их выход на публику в событие, нередко - мирового масштаба. На наш взгляд, имя Григория Зиновьева в этом смысле незаслуженно обойдено вниманием. По свидетельствам современников, Зиновьев был непревзойденным оратором, способным увлечь за собой массы.

Овсей-Герш Радомысльский, известный под именем Григория Зиновьева, был одним из ближайших соратников В. Ленина. До революции Г. Зиновьев находился в эмиграции, но, в отличие от Ленина, неоднократно приезжал в Россию для осуществления подпольной деятельности. Окончательно он вернулся на родину в 1917 году вместе с Лениным. Уже после Октябрьской революции Зиновьев стал председателем исполнительного комитета Коммунистического интернационала, а во время болезни Ленина вошел в так называемый триумвират, который, наряду с Зиновьевым, составляли Сталин и Каменев.

В нашей работе мы остановимся на исследовании ре- чевого имиджа политика Григория Зиновьева. Прижизненных аудиозаписей публичных выступлений Г. Зиновьева не сохранилось, тем не менее, языковая личность этого общественного деятеля представляет колоссальный интерес для лингвистов, политологов, социологов, поскольку именно Г. Зиновьев на протяжении многих лет входил в ближний круг В. Ленина, занимал различные руководящие посты и принимал непосредственное участие в разработке многих государственных документов.

Материалом для изучения послужили тексты публичных выступлений Григория Зиновьева, а также воспоминания его современников, позволяющие воссоздать речевой портрет этого политического деятеля.

Вот что пишет о Зиновьеве-ораторе Луначарский, с которым тот участвовал в одном из диспутов во время выборной кампании в преддверии IV съезда Российской социал - демократической рабочей партии (Стокгольмского, или «объединительного» съезда): «... я впервые услышал его как митингового оратора. Я сразу оценил его и несколько удивился: обычно такой спокойный и рыхлый, он зажигался во время речи и говорил с большим нервным подъемом. У него оказался огромный голос тенорового тембра, чрезвычайно звонкий. Уже тогда для меня было ясно, что этот голос может доминировать над тысячами слушателей. К таким замечательным внешним данным уже тогда присоединялась легкость и плав- 
ность речи, которые, как я знаю, вытекают из известной находчивости и замечательной логики, проистекающих от умения обнимать свою речь в целом и из-за частности не упускать основной линии. Все эти достоинства оратора развились потом у товарища Зиновьева планомерно и сделали его тем замечательным мастером слова, каким мы его теперь знаем» [7, с.27]. По мнению Луначарского, в России начала прошлого века Зиновьев как оратор уступал только Ленину и Троцкому. Высокую оценку дает Луначарский и Зиновьеву-публицисту: «Зиновьев как публицист отличается теми же достоинствами, что и Зиновьев-оратор, то есть ясностью и доступностью мысли и гладким, легким стилем» [7, с.27].

Лев Троцкий, входивший в левую оппозицию и до 1926 года (когда произошло объединение левой оппозиции с так называемой «новой оппозицией», которую возглавили Зиновьев и Каменев) являвшийся политическим оппонентом Зиновьева, тем не менее, высоко ценил его ораторские способности: «Зиновьев был оратором исключительной силы... Это был прирожденный агитатор, хотя противники называли Зиновьева наибольшим демагогом среди большевиков, он умел убеждать, завораживать сочувствующих нашей политической идеей» [9, с.217].

Мы согласны с мнением, что успех Октябрьской революции во многом зависел от умения ее вдохновителей вести диалог с массами, от владения ораторским искусством: «Начиная с приезда моего в Петербург, то есть с начала мая (раньше не знаю) и до самого Октябрьского переворота в Петербурге, было, так сказать, золотое время митингов. Казалось, массы не могли наслушаться, не могли насытиться новым словом» [6, с. 492].

В первые годы советской власти многие положения, озвученные Лениным, вышли из-под пера Григория Зиновьева. Так, именно Зиновьевым была написана известная резолюция II Всемирного Конгресса Коминтерна «О роли Коммунистической партии в пролетарской революции». Известно, что Ленин, который принимал участие в комиссии по ее редактированию, полностью одобрил ее и сам неоднократно цитировал этот документ в своих выступлениях и статьях. По сути, данная резолюция на долгие годы стала программным документом для коммунистов многих стран: «Лишь после того, как пролетарская диктатура лишит буржуазию таких могучих орудий воздействия, как пресса, школа, парламент, церковь, аппарат управления и т.п., лишь после того, как окончательное поражение буржуазного строя станет очевидным для всех, - в ряды Коммунистической партии начнут входить все или почти все рабочие» [2, с. 9].

По мысли французского социалиста Жоржа Сореля для того, чтобы мобилизовать массы на борьбу, необходимо конструировать мифы. Большевики не допускали подобных высказываний в своих работах и публичных выступлениях, поскольку определяли свою теорию как научную. Об этом пишет П.С. Гуревич, уделяя особое внимание марксистско-ленинской концепции идеологии [1, 39 - 40]. Тем не менее, большевикам не удалось избежать мифологизации своих убеждений. Так, Григорий Зиновьев, будучи председателем Петроградского Совета, сыграл ведущую роль в формировании так называемого «петербургского мифа». Ленин в своих работах выделил питерских пролетариев лишь как особую группу рабочего класса: «Питер - не Россия. Питерские рабочие - малая часть рабочих в России. Но они - одни из лучших, передовых, наиболее сознательных» [5, с.25]. Зиновьев же пошел дальше. Он понимал, что только лозунгов и воззваний будет недостаточно для того, чтобы повести за собой массы. Необходимо было аргументированно и последовательно изложить «историю происхождения» рабочих Питера, доказать существование традиций: «Каждый мыслящий пролетарий начинает свою историю не только 25 октября. Каждый рабочий-коммунист хочет иметь определенное мировоззрение, он хочет иметь не только резолюцию по текущему моменту, он хочет иметь свой взгляд на вещи, он хочет знать, как создавался наш мир» $[10$, с. 10]. Глава Петросовета беспрестанно, во многих своих выступлениях и публикациях говорил о том, что именно Петроград стал ареной главных исторических событий: «Тут каждый камень есть кусок истории русской революции» [3, с.7]. С точки зрения выбранной методологии, на наш взгляд, это был весьма удачный ход, поскольку «...как и традиционные, современные мифы имеют особую логическую структуру, отличную от рационального мышления: не соблюдается закон исключенного третьего, суть подменяется происхождением, событиям приписывается обязательная целенаправленность, соседство во времени принимается за причинно-следственную связь» [8, с.17]. Таким образом, создание «петербургского мифа» способствовало сплочению питерских рабочих, и, как следствие, помогало решать определенные политические задачи.

Для того, чтобы быть максимально объективными в описании личности Григория Зиновьева, по нашему мнению, следует упомянуть о фактах, которые характеризуют его с отрицательной стороны. В истории нашей страны Григорий Зиновьев остался как человек, который вел непримиримую борьбу с питерской интеллигенцией. Занимая пост председателя Петросовета, он имел неограниченные полномочия и стал главным организатором так называемого «красного террора» в Петрограде. Так, в 1921 году по постановлению Петроградского Совета были расстреляны участники «заговора Казанцева», в число которых входил и поэт Николай Гумилев. При этом Зиновьев, будучи исключительным демагогом, умело использовал созданный при его активном участии «петербургский миф» для оправдания своих политических решений: «...будет величайшим счастьем, когда представители лучшей части интеллигенции поймут, что то, 
что происходит сейчас, это не заговор отдельных людей... ленинградские пролетарии есть та соль пролетарской земли, которые вынесли на своих плечах тяжесть трех великих революций. Ленинградские пролетарии были той массой, которая выдвинула такого вождя, как В.И. Ленин» $[10$, с.9].

Как мы видим, Г. Зиновьев действительно обладал выдающимися ораторскими способностями. Более того, как и Ленин, он осознавал важность публичных выступлений в формировании общественного мнения.

Итак, публичные выступления являются неотъемлемой частью деятельности политика, при этом «...речевой имидж политика играет существенную роль в формировании образа страны как в мире в целом, так и в сознании его сограждан» [4, с. 2474]. Воплощение идеи в любой области, будь то политика, экономика или социальная сфера, во многом зависит не только от мыслей, вложенных в эту идею, но и от способа ее ретрансляции. Современная теория коммуникации отводит ключевую роль «каналу коммуникации» в процессе воздействия на реципиента информации. В данном случае определяющими факторами успешного взаимодействия с аудиторией являются оратор с его индивидуальной речевой манерой и способы подачи информации, которые он использует. Языковая личность Григория Зиновьева в полной мере подтвержает эту мысль: многие преобразования, пропагандируемые теоретиками Октябрьской революции, стали возможными во многом благодаря виртуозному владению политиками (в частности - Зиновьевым) мастерством публичной речи.

\section{ЛИТЕРАТУРА}

1. Гуревич П.С. Социальная мифология - М.: Мысль, 1983. - 175 с.

2. Зиновьев Г. История Российской коммунистической партии (большевиков) / Популярный очерк, издание 5-е. - Государственное издательство «Ленинград», 1924 г. -263 с.

3. Зиновьев Г. Петроград // Красноармеец - № 10. - С. 7.

4. Кучменко М.А. Новогоднее обращение главы государства к нации как эффективная PR - технология // Инновации. Наука. 06разование, 2020. - № 23. C. $2472-2478$.

5. Ленин В.И. 0 питерских рабочих. - Л., 1960. - С. 25.

6. Луначарский А.В. Силуэты. - М.: Молодая гвардия, 1965 г. - 542 с.

7. Луначарский А.В. Сборник работ. - М.: Директ-Медиа, 2014. - 57 с.

8. Неклюдов С.Ю. Структура и функции мифа //Мифы и мифология в современной России / Под ред. К. Аймермахера, Ф. Бомсдорфа, Г.А. Бордюгова. М.: AИPO-XX, 2000. -216 C.

9. Троцкий Л.Д. К истории русской революции. - М., 1990. - 448 с.

10. Цит. по: Смирнов А.П. Петербургский миф Григория Зиновьева // История Петербурга. 2006. № 4. - С. 9-12.

(c) Кучменко Марина Александровна (kuchmenko_m0406@mail.ru). 